\title{
The Nature of Technology Consumption among School Children in Lower Northern Thailand
}

\author{
https://doi.org/10.3991/ijim.v13i05.10309 \\ Hsu Nang $(\bowtie)$, Antony Harfield \\ Naresuan University, Phitsanulok, Thailand \\ nangh57@email.nu.ac.th
}

\begin{abstract}
The use of mobile computational devices among school children is increasing in developing countries. In order to clarify the trends of consuming technological devices, a survey study was carried out with 4,231 students across from the lower northern part of Thailand at an annual science fair between 2014 and 2017. The key findings illustrate smartphone usage is dramatically increasing while PC and tablet usage is not stable in each year. It is becoming an essential technological device to access for the various purposes in students daily activities. Nonetheless, PCs is still heavily using as teaching aid material at school even they are more likely to access the portable computational devices such as tablets and smartphones than PCs. The breakdown study presents male students love to play games on all kinds of mobile devices than female. The evidences demonstrate mobile consumption amongst Thai school children is shifting towards positive and negative sides. Therefore, the constructive manner of technology consumptions might be varied on some influence factors such as individual knowledge, educational policy, parental controls and teachers' attitudes towards using mobile devices at class.
\end{abstract}

Keywords-Technology usage; technology adoption; demographics; smartphones; tablets

\section{Introduction}

The availability of technological devices, the arrival of social media and internet make the changes of our societies [1]. Technological devices and a wide variety of online/offline applications become a part of young people essential and simply familiarize with it from an early age. Mobile devices as smartphones, tablets, laptops and applications are available with affordable prices for everyone to use multipurpose [2]. The technology advancement and widespread accessibility of computational device integrate into every one's life to interact on social media, access new knowledge, and learning [3]. Thus, mobile devices are popular as ubiquitous tools which can be used at work, school and home for leisure, study or different purposes.

A study shows under 20-year-old age group is becoming the fastest growth in accessing the internet and computational devices [4]. 88.7\% of grade four, five, and six students are particularly accessed computers, where over $70 \%$ surfed the internet at 
their homes [5]. The evidence illustrates children are freely to access PCs for their leisure purposes than to use as learning aid tools at school. In Singapore, PCs and smartphones are the most essential computational devices, where tablets have the least access [6]. The result is similar as the consumption of technological devices among primary and secondary students in Thailand [7][8].

Besides, schools are allowing the students to use smartphones for educational purposes at class, where $51 \%$ of students are bringing and accessing their smartphones at class every day [9]. The different types of activities could occupy on any kinds of mobile devices among students. Play game activity was the most popular activity amongst primary school children and followed by educational activities [6]. The social media is another medium for students which is becoming student preferences in the informal learning and teaching process [10]. They prefer to use Skype the most, followed by Facebook as the second and Whatsapp, Twitter, and mobile SMS were the least as the learning engagement tools. Students have the positive attitudes and willing to access the social media as their daily learning processes. As described from the world economic forum in 2016, 60\% of students like to access web on PCs or laptops, and $30 \%$ is from mobile devices [11]. The survey evidence from Childwise presented $41 \%$ for playing game, $51 \%$ is watching video while $54 \%$ used their smartphones to listening music, and $60 \%$ surf the internet on their mobile phones [12]. Additionally, they prefer to do multitasking on listening and downloading music while using computers. The situation demonstrates the integration of social media in teaching and learning process is a successful technological use informally.

The literature reviews state the popularity of mobile devices among primary and secondary students. The consuming of play, learn and social activities of their daily routines are depending on the different age groups. This is a trending and we initially would like to know Thai students' technological preferences in their daily lives. Thus, a research needs to focus on what they use for, how they access on the various kinds of contents to prevent from harmful outcomes.

\section{Background of a New Proposed Framework}

The purpose of this paper is to describe a survey undertaken to analyze technology usage on different computational devices among school children. The survey was carried out once per year between 2014 and 2017 with primary and secondary school children in the lower northern part of Thailand. In total, there were over 4,213 participants in this survey was analyzed using statistical methods in terms of a) the penetration and frequency of $\mathrm{PC}$, tablet and smartphone usage, b) the location of use, c) the purposes such as education, playing games, contacting with friends, and watching movies, d) differences in usage between age groups (P1-3, P4-6, M1-3, M4-6), and e) genders. The simple excel statistics method was used to analyze the data. Each aspect was analyzed by year of survey to show the trends of technology consumption. The survey questions are shown in the following table 1 . 
Table 1. Content of the questionnaire

\begin{tabular}{|c|c|}
\hline Question & Answers \\
\hline $\begin{array}{l}\text { Gender } \\
\text { Age } \\
\text { Year of study }\end{array}$ & \\
\hline $\begin{array}{l}\text { Do you use computer (PC)? } \\
\text { How often do you use computer? } \\
\text { Where do you use computer? } \\
\text { What do you use computer for? }\end{array}$ & $\begin{array}{l}\text { Yes / No } \\
\text { Every day / 3-4 times per week / 1-2 times per week. } \\
\text { School only /Home only / School and home only. } \\
\text { Education /Playing games / Contacting friends / Browsing } \\
\text { internet / Watching video. }\end{array}$ \\
\hline $\begin{array}{l}\text { Do you use tablets? } \\
\text { How often do you use tablet? } \\
\text { Where do you use tablet? } \\
\text { What do you use tablet for? }\end{array}$ & $\begin{array}{l}\text { Yes / No } \\
\text { Every day / 3-4 times per week / 1-2 times per week. } \\
\text { School only / Home only / School and home only. } \\
\text { Education /Playing games / Contacting friends / Browsing } \\
\text { internet / Watching video. }\end{array}$ \\
\hline $\begin{array}{l}\text { Do you use smartphone? } \\
\text { How often do you use smartphone? } \\
\text { Where do you use smartphone? } \\
\text { What do you use smartphone for? }\end{array}$ & $\begin{array}{l}\text { Yes / No } \\
\text { Every day / 3-4 times per week / 1-2 times per week. } \\
\text { School only /Home only / School and home only. } \\
\text { Education /Playing games / Contacting friends / Browsing } \\
\text { internet / Watching video. }\end{array}$ \\
\hline
\end{tabular}

\section{$3 \quad$ Result}

\subsection{Overall observations}

We started by examining the current situation and the overall trends. Figure 1 shows that in 2017 smartphones are used by approximately $90 \%$ of children, PCs by $80 \%$ and tablets by 50\%. It also shows that between 2014 and 2017 the trend is increasing numbers of children using smartphones and PCs. Smartphone usage has increased at the fastest rate, approximately $5 \%$ per year ( $\sim 20 \%$ over 4 years). PC usage has increased by $2-3 \%$ per year $(\sim 10 \%$ over 4 years). However, tablet usage has remained relatively stable (around 50\%) over the same period.

When we looked at how frequently that children use these devices, we found that the majority of smartphone users are using them every day. Figure 2 shows the frequency of usage for the three types of device. More than $70 \%$ of smartphone users are using them every day. Approximately $40 \%$ of tablet users are using them every day. The least frequently used device was the PC, which was only used every day by approximately $25 \%$ of users. Therefore, while PCs are more popular than tablets, those users with tablets use them more often than PCs. The results suggest that the more portable the device, the more frequently it is used by children. 


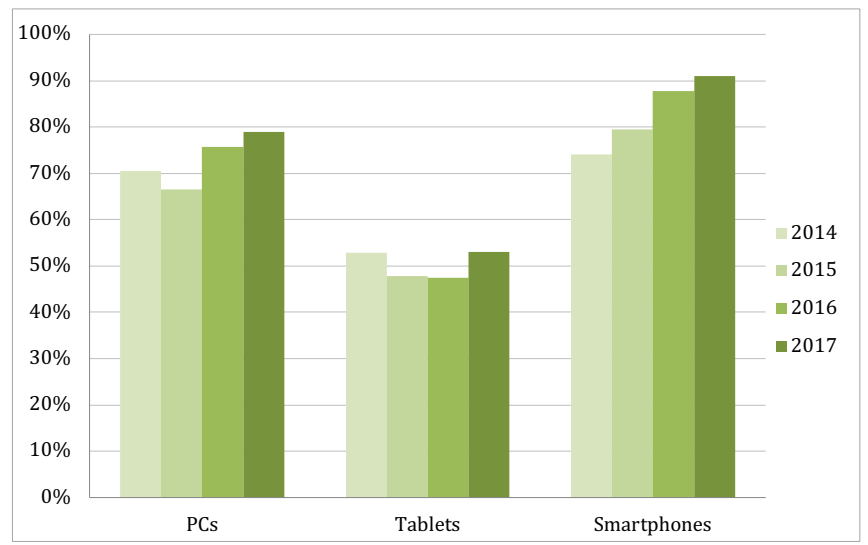

Fig. 1. What percentage of children use PCs, tablets and smartphones?

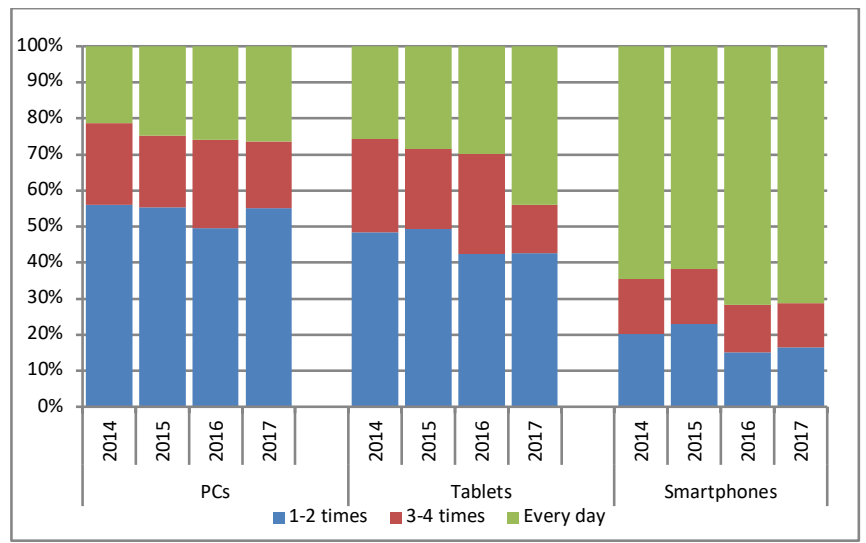

Fig. 2. How often do children use PCs, tablets and smartphones?

Figure 2 also shows the change in frequency between 2014 and 2017. Tablet usage has increased the most significantly, from $26 \%$ of every day users in 2014 to $44 \%$ of every day users in 2017. PCs and smartphones, however, have seen only a slight increase (less than 5\%) in every day users over the same period.

When children use technology, the most popular purpose of use is either playing games or watching movies whatever type of device is used, as illustrated in Table 2. For game playing, tablets and smartphones have been consistently used more than PCs by between $5 \%$ and $15 \%$ over the 4 years. For watching movies, smartphones have become slightly more popular than PCs and tablets in the last year. The third most popular usage of smartphones is messaging or talking with friends, and this purpose of usage is considerably greater on smartphones than other devices.

Instead, on PCs and tablets we find that educational activity (e.g. doing homework) is more common than smartphones over the last 4 years. However, the use of 
smartphones for education is on the increase and has overtaken PCs and tablets in 2017.

Table 2. What do children use PCs, tablets and smartphones for?

\begin{tabular}{|l|c|c|c|c|c|c|c|c|c|c|c|c|}
\hline & \multicolumn{4}{|c|}{ PCs } & \multicolumn{4}{c|}{ Tablets } & \multicolumn{3}{c|}{ Smartphones } \\
\cline { 2 - 13 } & $\mathbf{2 0 1 4}$ & $\mathbf{2 0 1 5}$ & $\mathbf{2 0 1 6}$ & $\mathbf{2 0 1 7}$ & $\mathbf{2 0 1 4}$ & $\mathbf{2 0 1 5}$ & $\mathbf{2 0 1 6}$ & $\mathbf{2 0 1 7}$ & $\mathbf{2 0 1 4}$ & $\mathbf{2 0 1 5}$ & $\mathbf{2 0 1 6}$ & $\mathbf{2 0 1 7}$ \\
\hline Education & $67 \%$ & $41 \%$ & $46 \%$ & $45 \%$ & $39 \%$ & $26 \%$ & $34 \%$ & $38 \%$ & $32 \%$ & $29 \%$ & $42 \%$ & $46 \%$ \\
\hline Play games & $34 \%$ & $45 \%$ & $48 \%$ & $65 \%$ & $52 \%$ & $58 \%$ & $54 \%$ & $69 \%$ & $41 \%$ & $50 \%$ & $60 \%$ & $69 \%$ \\
\hline $\begin{array}{l}\text { Communi- } \\
\text { cation }\end{array}$ & $24 \%$ & $21 \%$ & $32 \%$ & $31 \%$ & $23 \%$ & $21 \%$ & $31 \%$ & $39 \%$ & $53 \%$ & $43 \%$ & $53 \%$ & $54 \%$ \\
\hline Watch movies & $23 \%$ & $27 \%$ & $45 \%$ & $65 \%$ & $27 \%$ & $27 \%$ & $52 \%$ & $64 \%$ & $28 \%$ & $28 \%$ & $50 \%$ & $72 \%$ \\
\hline
\end{tabular}

Table 3 describes where children are most likely to use technology devices. The majority of tablet and smartphone usage is at home, whereas PC usage is more evenly spread between school and home (in 2017 there was only 10\% more home users). Children prefers to access the portable computational devices at home than school location. The use of tablets, smartphones and PCs at school is currently at $23 \%, 43 \%$ and $64 \%$ respectively.

Table 3. Where do children use PCs, tablets and smartphones?

\begin{tabular}{|l|c|c|c|c|c|c|c|c|c|}
\hline \multirow{2}{*}{ Year } & \multicolumn{2}{|c|}{ PCs } & & \multicolumn{2}{c|}{ Tablets } & \multicolumn{2}{c|}{ Smartphones } \\
\cline { 2 - 8 } & & School & Home & & School & Home & & School & Home \\
\hline 2014 & & $63 \%$ & $66 \%$ & & $16 \%$ & $94 \%$ & & $42 \%$ & $97 \%$ \\
\hline 2015 & $54 \%$ & $80 \%$ & & $17 \%$ & $96 \%$ & & $41 \%$ & $97 \%$ \\
\hline 2016 & $62 \%$ & $74 \%$ & & $27 \%$ & $89 \%$ & & $54 \%$ & $96 \%$ \\
\hline 2017 & $64 \%$ & $74 \%$ & & $23 \%$ & $91 \%$ & & $43 \%$ & $97 \%$ \\
\hline
\end{tabular}

\subsection{Age group differences}

While smartphones are the most commonly used device overall, in the youngest age group (P1-3, corresponding to first 3 years of school, aged 7-9 years old) smartphones are the least commonly used devce. Figure 3 shows how smartphone usage accelerates rapidly among the P4-6 group (aged 10-12 years old) and becomes the most dominant device from that group onwards. In the youngest age group, PCs are more commonly than tablets and smartphones. Tablet usage is lowest in the oldest group (M4-6, aged 16-18 years old) which tends to suggest that as smartphone usage goes up the tablet usage decreases. However there is an anomoly in that tablet usage is significantly high in the M1-3 group (aged 13-15 years old) - it is unclear why this particular age group uses the tablet more than other age groups. 


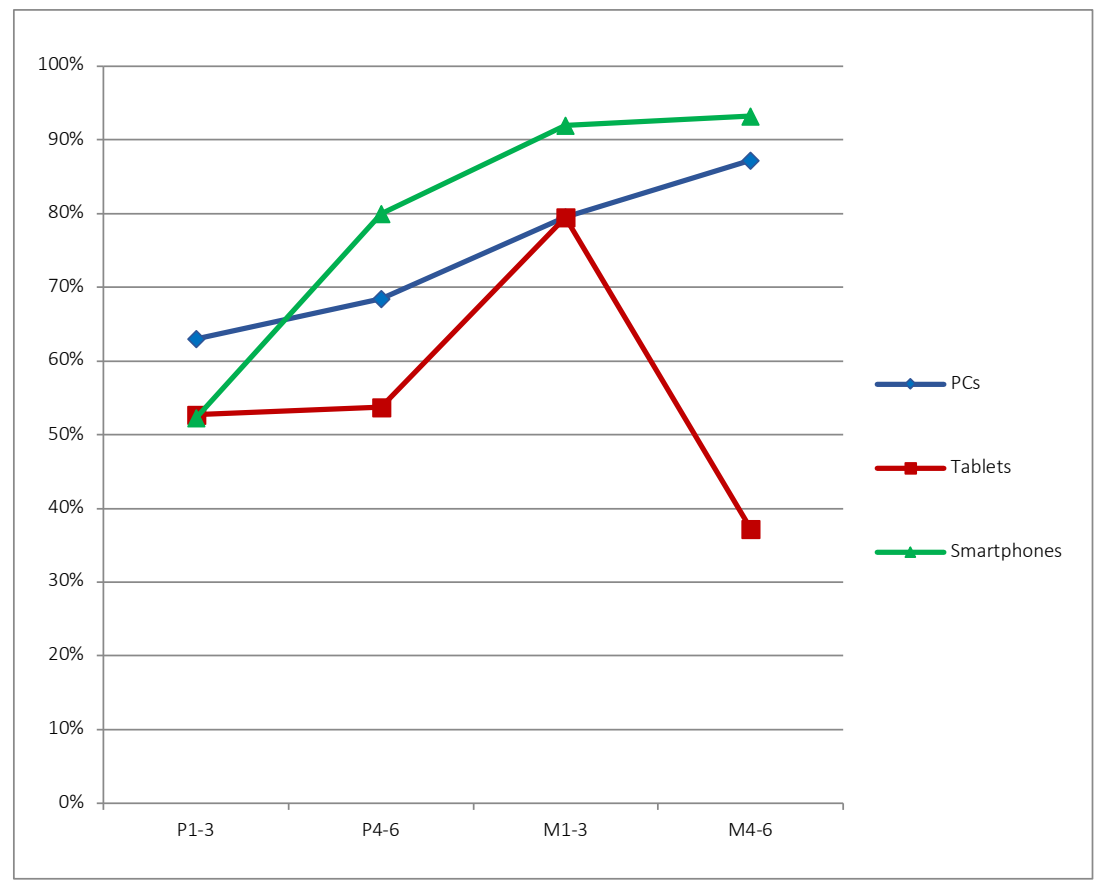

Fig. 3. How does device usage vary by age groups?

\subsection{Gender differences}

There are small differences overall in technology choice between boys and girls as shown in Figure 4 (a). We found that 6\% more boys used PCs than girls, whereas 3\% more girls used smartphones than boys. There was little difference in the number of boys and girls using tablets. There were much greater differences in the activities of boys and girls when using the devices, as shown in Figure 4 (b). On smartphones particularly, differences were clear: boys were more than twice as likely to play games than girls; using the devices for communication was considerably more popular for girls than boys. This trend of boys playing games and girls communicating is evident across PCs and tablets too. Watching movies was considerably more common for girls on smartphones, whereas watching movies was similarly common for boys and girls on PCs and tablets. The use of devices for education (e.g. doing homework) was higher for girls no matter which device was used. Education was the most popular activity for girls using PCs. 

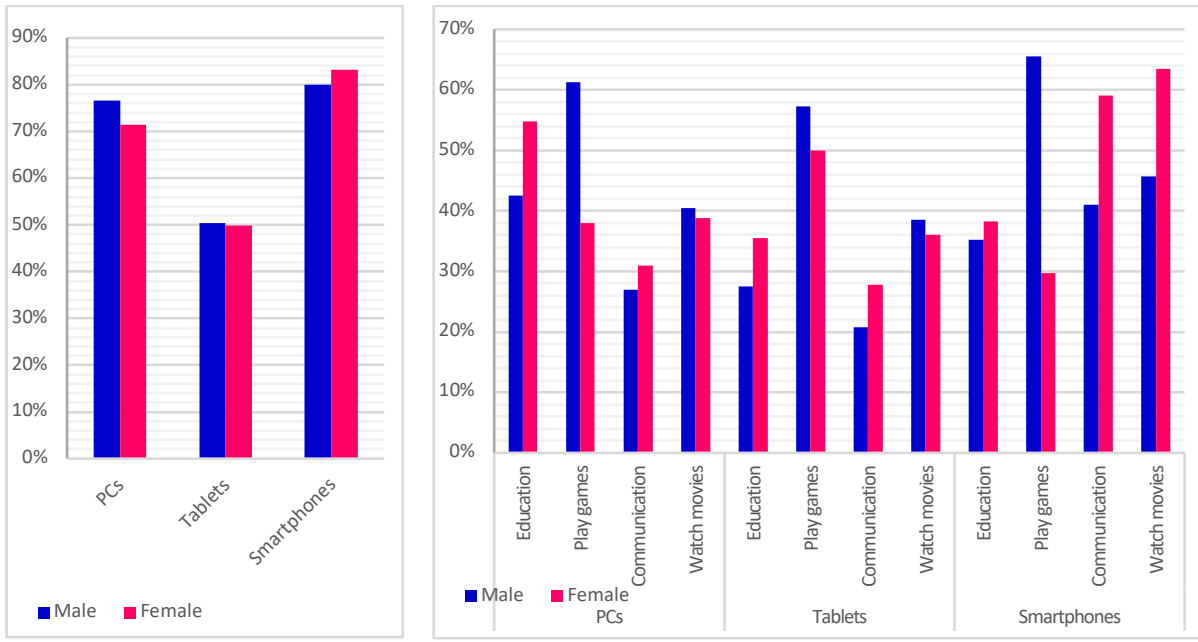

Fig. 4. How does device usage vary by gender (a) overall; and (b) in terms of activity?

\section{$4 \quad$ Discussion and Conclusion}

The use of smartphones by children has been steadily rising over the last 5 years and now stands at above $90 \%$ adoption. This is not surprising - it is common for children to own or have access to a smartphone. They are also engaging in a wider range of activities with smartphones. Whereas in 2014 the major use case was communicating with friends and family (from Table 2), now children are more likely to use smartphones for watching movies or playing games. The smartphone is also increasingly being used for educational purposes. Overall, we are seeing that smartphones are taking more and more of the activities that children traditionally used a desktop computer for. The prominent activity for boys is playing games and for girls is watching movies-and both groups are currently using smartphones more than PCs for these activities.

From the dominant picture painted of smartphone usage, it might be expected that the PC is becoming less popular with children. That's not the case. PC usage among children has consistently increased year on year between 2014 and 2017. For younger children, particularly the group aged 7-9 years old, PC usage is more common than smartphone usage. PCs still have the highest usage of any device in schools, with $64 \%$ of children using PCs in school. Therefore we can presume that parents and teachers still value PCs for education. In addition, the fastest growing activity for children using PCs is watching movies, while the overall most popular activity is playing games, so we can assume that children still enjoy PCs as an entertainment platform. It would suggest that parents are still purchasing PCs for their homes and encouraging children to use them. One of the advantages of the PC is that it is typical to share it between children and their parents, and the PC is able to be used by many family members at once - e.g. for watching movies or playing games. Perhaps some of the PCs continued popularity is that it is a more social device than a smartphone. 
Unlike smartphones and PCs which are used by more than $80 \%$, tablets are only used by $50 \%$ of children. The majority of tablet usage occurred at home. Tablets can be seen as a compromise between smartphones and PCs. They enjoy the portability of small devices but with a larger screen that makes them popular for watching movies and playing games similar to PCs. They could be a personal device (e.g. one per child) or they could be a shared device (e.g. one per household). Most likely is that parents currently perceive tablets as a "luxury" item (similar to how PCs were viewed 20 years ago) with little value over the existing PC and smartphone they own. Furthermore, few schools are investing in tablets (either as shared resources or as personal tools for each child). Unless school adoption increases, or parent perceptions change, tablets are going to continue to be the least popular of the three devices as the results above confirm.

The overall results presented in this paper are consistent with other countries use of the three device types - in a survey by Deloitte of technology usage in the UK [16] found smartphones, laptops and tablets were used by approx. $90 \%, 80 \%$ and $60 \%$ respectively. Tablets are therefore slightly less popular in Thailand than other countries. This could be due to less opportunity to use tablets as one report from New Zealand suggests that children prefer to consume content on tablets rather than other mobile devices [13]. However, in a separate study from Childwise 5-16 year old children preferred to use smartphones and it was their top device for the entertainment [12]. In this respect, the literature shows that preferences for device usage can vary by demographics.

Even with the current study, usage varied significantly by age group and gender. As children grow older, their technology usage will change - not just how they use it but also the device they use for each activity. The simplistic stereotypes that have developed around technology (particularly gender biases) can be challenged. These results highlight some new questions around preference for technology depending on gender: are boys more attracted to use PCs and girls more attracted to smartphones or are parents more likely to provide a PC for boys and a smartphone for girls? One thing is for sure, tablets appear to balance gender differences - equal numbers of girls and boys used tablets and the activities (education, games, communication, and movies) were more evenly matched than PCs or smartphones.

The finding is similar from a separate study, which illustrated school children are likely to access for chatting, uploading photos via Facebook or MSN, playing online games, surfing the internet [14]. They prefer to search sports, games, music, videos and shows than school lessons.

Besides, the similar result from Singapore presented playing games, e-learning activity and watching movies on YouTube or online is popular activities amongst school children [6]. The authors highlighted parents are positioned the clear boundaries to prevent them from overuse of technology. $95 \%$ of children prefer to play games on their mobile devices even parents are concerning for their health such as not to strain eyes and sleep deprivation. Singaporean parents are attempted to regulate computational devices and surf the internet. The evidences show media consumption is shifting towards positive and negative sides in Asian countries. 
The significant result illustrates students in Thailand are predominately consumed for play game activity. Besides, the nature of educational purposes use on tablet and smartphone has similar patterns among Thai school children. The trend of using technology devices is varying every year and children like to access the portable devices at home location. Both male and female student prefer to access them for the entertainment purposes. Therefore, the future study will conduct the deep analysis on the parental control on the nature of technology use. We believe that it could help to figure out the possible reason of shifting the positive and negative consuming sides of mobile computational devices in Thailand.

\section{$5 \quad$ References}

[1] Ludlow, B. L., \& Duff, M. C. (2009). Evolution of distance education at West Virginia University: Past Accomplishments, Present Activities, and Future Plans. Rural Special education Quaterly, Vol. (28), No. (3). https://doi.org/10.1177/875687050902800304

[2] Johnson, L., Adams, S., Cummins, M., Estrada, V., Freeman, A., \& Ludgate, H. (2013). The NMC Horizon Report: 2013 K-12. New Media Consortium.

[3] Samaha, M., and Hawi, N. S. (2016). Relationships among smartphone addiction, stress, academic performance, and satisfaction with life. Comput. HumanBehav. 57, 321-325. doi:10.1016/j.chb.2015.12.045. https://doi.org/10.1016/j.chb.2015.12.045

[4] Michelet, I. (2003). Our Children at Risk Online: The Example of Thailand: Survey Report. ECPAT International.

[5] Quigley, D. (2011). Internet and Independent E-Learning of School Age Children in Thailand (One Study). Online Submission.

[6] Goh, W. W., Bay, S., \& Chen, V. H. H. (2015). Young school children's use of digital devices and parental rules. Telematics and Informatics,32(4), 787-795. https://doi.org/10.10 16/j.tele.2015.04.002

[7] Harfield, A., Nang, H., Nakrang, J., \& Viriyapong, R. (2014, December). A Survey of Technology Usage by Primary and Secondary School Children in Thailand. In The Eleventh International Conference on eLearning for Knowledge-Based Society (pp. 11-13).

[8] Nang, H., Harfield, A., \& Viriyapong, R. The Current State and Emerging Trends of Technology Usage among Young People in Thailand.

[9] Grunwald Associates LLC. (2013). Living and Learning with Mobile Devices: What Parents Think About Mobile Devices for Early Childhood and K-12 Learning.

[10] Afzal, M. T., \& Fardous, N. (2016). Students' Preferences of Technology Usage for Their Learning Engagement. American Journal of Educational Research, 4(10), 749-751.

[11] World Economic Forum. (2016). Digital Media and Society Implications in a Hyperconnected

Era. http://www3.weforum.org/docs/WEFUSA_DigitalMediaAndSociety_Report2016.pdf

[12] Childwise (2017). The monitor trends report: Trends data from the CHILDWISE MONITOR Report 1997-2016.

[13] BSA. (2015). Children's Media Use Study How our children engage with media today. Broadcasting Standards Authority, New Zealand. Available: https://bsa.govt.nz/images/assets/Research/Childrens_Media_Report_2015_FINAL_for_pu blishing_2.pdf

[14] Pini, M., Musanti, S. I., \& Pargman, T. C. (2014). Youth digital cultural consumption and education. Designs for Learning, 7(2). https://doi.org/10.2478/dfl-2014-0063 
[15] Lee, P. (2018). Deloitte Global Mobile Consumer Survey: UK Edition, Jun 2018. Available: http://www.deloitte.co.uk/mobileuk/

\section{Authors}

Hsu Nang, Department of Computer Science and Information Technology, Faculty of Science, Naresuan University, Phitsanulok, Thailand.

Antony Harfield, Department of Computer Science and Information Technology,

Faculty of Science, Naresuan University, Phitsanulok, Thailand. (e-mail: antonyh@email.nu.ac.th)

Article submitted 2019-02-12. Resubmitted 2019-03-02. Final acceptance 2019-03-04. Final version published as submitted by the authors. 